\title{
NEWS
}

\section{Good chemical manufacturing process criteria}

\author{
John A. Glaser
}

Published online: 20 February 2014

(C) Springer-Verlag Berlin Heidelberg (outside the USA) 2014

A tenfold increase in $\mathrm{R} \& \mathrm{D}$ expenditures has been experienced by research-based pharmaceutical companies over the past 25 years. It is incumbent upon these producers to find ways to reduce manufacturing costs. One approach that uses innovative developments leads to targeted product structures and workflow has been assembled by contributors from Boehringer Ingelheim Pharma \& Pharmaceuticals. A series of eight criteria: material cost, process efficiency, yield, volume-time-output (VTO), environmental factor (E factor/process mass intensity), quality service level, process excellence index, and modified EcoScale were found to greatly support cost-saving efforts. Many of these components have received extensive attention in the literature. The individual contributions of the criteria to the chemical process development offer a significant aid to query each stage of synthetic development for improved good manufacturing practice. For instance synthetic planning in a linear format can be improved through considerations of convergent synthetic approaches to the target chemical.

Linear synthesis plan

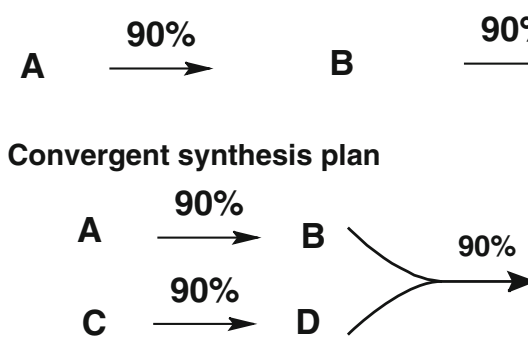

J. A. Glaser $(\bowtie)$

National Risk Management Research Laboratory, US

Environmental Protection Agency, 26 W King Dr, Cincinnati, OH 45268, USA

e-mail: Glaser.John@epa.gov
A highly useful EcoScale template accompanies the article to permit an understanding of the analysis at a glance. A weighting factor scheme for the use of the eight criteria for a good chemical process is offered to facilitate the overall analysis. Criteria weighting is expected to change for different process optimization objectives and economic priorities.

Org Process Res Dev 2012, 16, 1697-1706.

\section{Benefits of machine-to-machine technologies}

A 52-page report, Machine to Machine Technologies: Unlocking the Potential of a \$1 Trillion Industry, claims that selected technologies could significantly reduce greenhouse gas (GHG) emissions by 2020. Machine-tomachine technology (M2M) is a developed competence enabling physical infrastructure to connect to each selected device and exchange information to sensors, wireless net-

\section{C $\stackrel{90 \%}{\longrightarrow}$ Product \\ Overall yield $=\mathbf{9 0} \% \times \mathbf{9 0} \% \times \mathbf{9 0} \%=\mathbf{7 3} \%$}

Product Overall yield $=90 \% \times 90 \%=81 \%$

works, analytical software, and IT infrastructure. M2M applications in the energy, transportation, building management, and agriculture sectors were found to offer the greatest potential for profitably reducing GHG emissions by more than $1.5 \mathrm{Gt}$ of carbon dioxide equivalents $\left(\mathrm{CO}_{2} \mathrm{e}\right)$ 
by 2020 . Where today's complex industrial society can optimize operations, M2M could offer solutions to resource scarcity and climate change. The authors assert that "low carbon" could be synonymous with economic growth and sustainable prosperity, if M2M technologies are employed to their full potential. It is anticipated that there will be 12.5 billion M2M devices globally by 2020 compared with1.3 billion devices today. Economic benefits of the M2M industry are expected to maintain receptor amenable to a wide range of separation applications, i.e., chromatography, catalysts, sensors, drug delivery, purification, and sample pretreatment. MIPs are formed in a polymer matrix in which a template is present during the polymerization process after which the template molecules are removed through thorough washing. The polymerization mixture is composed of functional monomer(s), cross-linking monomer, template, and polymerization initiator in an appropriate solvent.
Template<smiles>CC(C)Cc1ccc(C(C)C(=O)O)cc1</smiles>

Ibuprofen
Functional monomer<smiles>C=C(C)C(=O)O</smiles>

Methacrylic acid

\section{Crosslinking monomer}<smiles>C=Cc1ccc(C=C)cc1</smiles>

Divinyl benzene
$23 \%$ annual growth rates over the next decade, and today's $\$ 121$ billion business will be worth $\$ 948$ billion by 2020 . Smart meters and energy efficient building systems with other M2M could potentially save 9 billion metric tons of greenhouse gas emissions annually by 2020 .

The report claimed that $\mathrm{M} 2 \mathrm{M}$ could reduce $\mathrm{GHG}$ emissions by 9.1 billion metric tons of carbon dioxide equivalent annually by 2020 , which is equal to $18 \%$ of total global emissions in 2011.

The international goal of preventing an average global temperature rise of $2{ }^{\circ} \mathrm{C}\left(3.6^{\circ} \mathrm{F}\right)$ requires global $\mathrm{GHG}$ emissions reductions of up to 7 billion metric tons of $\mathrm{CO}_{2} \mathrm{e}$, or $10-15 \%$ of today's emissions.

AT\&T, the Carbon War Room, and the School for Creative Leadership partnered to produce this report. The Carbon War Room is a U.S. nonprofit organization founded by U.K. billionaire and Virgin Atlantic Airways Ltd. founder Richard Branson. The organization aspires to encourage development and implementation of clean technologies to address climate change.

http://www.grahampeacedesignmail.com/cwr/cwr_m2m_ down_singles.pdf.

\section{Molecular imprinted polymers (MIPs) in separation}

Polymeric materials have significantly contributed to different aspects of separation science ranging from reactive coatings to polymer composites. New technology involves the functionalization of polymers to form an artificial
The polymeric matrix shows enhanced affinity for the template molecule in contrast to other similar molecules. The designed template grooves in the matrix provide the properties on which the separation is based. A variety of embodiments have been used to exploit the properties of MIPs such as ground particles, spherical particles, nanoparticles, monoliths, surface attached thin layers, membranes, and composites. A widely ranging future is anticipated for MIPs extending from nanotechnology, microfabrication technology, and membranes to sensing transducer elements.

J Sep Sci 2013, 36, 609-628.

\section{Business resilience to climate change}

Extreme weather events are recognized for their potential to produce adverse conditions leading to the alteration or cessation of business. The accompanying risk is still poorly anticipated by current business policy. Extraordinary events such as droughts in the U.S. Midwest, severe heat waves in Europe, damaging floods in Thailand, and destructive storms in Australia and the United States are but a few of the events of the past 3 years prefigure the future challenges brought by changing climate condition.

A recent report issued by the Center for Climate and Energy Solutions (C2ES), Weathering the Storm: Building Business Resilience to Climate Change attempts to identify a framework of directions useful to business planning developing resilience to conditions presented by climate change. 
Sea level rise and coastal surge accompanying powerful storms could devastate many of shoreline or near-shore infrastructures. Estimated losses from a 100-year category storm have been estimated to range from $\$ 58$ to $\$ 84$ billion. The "Superstorm" Sandy traumatized the New York/ New Jersey megopolis in 2012 where the estimated damages amount to more than $\$ 65$ billion.

Many companies are questioning what is normal or have they entered a "new normal." What steps should be taken to build corporate resilience to these increased risks. Yet there is uncertainty regarding the precise nature and timing of changes in climate and extreme weather risks. Understanding the likelihood and severity of impacts remains a significant challenge for companies deciding how and when to invest in resilience beyond "business as usual." As a result, business activities to build resilience are largely a continuation of existing practices and policies that are based on a historical picture of past risks, and often fail to sufficiently consider changing climate and weather conditions. Thus, the most common strategy for addressing climate-related risks leaves most companies without the resilience they need to weather future physical impacts of climate change.

The Center for Climate and Energy Solutions (C2ES) is successor to the Pew Center on Global Climate Change as an independent, nonprofit, nonpartisan organization promoting strong policy and action to address the twin challenges of energy and climate change.

http://www.c2es.org/publications/weathering-storm-buildingbusiness-resilience-climate-change.

http://www.c2es.org/docUploads/business-resiliencereport-07-2013-final.pdf.

\section{Capital expenditures effect on biotechnology patenting}

The biotechnology industry was selected to identify mechanisms controlling patent output for small and large firms, involving both entrepreneurial and established enterprise. The analysis was based on indirect knowledge acquired from capital expenditures and direct knowledge of in-house $\mathrm{R} \& \mathrm{D}$. Biotechnology was identified as a good model business for this study for its versatility and its hybrid industries situated in a knowledge-intensive group of interactive platforms. The variety of products (biopharmaceuticals, vaccines, industrial enzymes, biological pesticides, crop seeds, bio-reagents, DNA chips, DNA analysis tests, and medical diagnostic kits) offer a wide landscape to mine for information. Biotechnology can be envisioned as an aggregate in which product innovation, where both sequential and complementary discovery processes are driven by process innovation, capital costs of new machinery, and equipment.
The report sought to answer two queries (1) "how does the interaction of rising demand with the availability of new technological opportunities determine a firm's mix of capital and R\&D investment?"; (2) "are there significant differences in the attitude of large and small firms towards capital and R\&D investment?"

Patent applications, R\&D investment, and capital expenditures were studied using statistical models. The EU Industrial R\&D Investment Scoreboard, the European Patent Office (EPO), the US Patent and Trademark Office, and the World Intellectual Property Organization were sources of pertinent information for the time period 2002-2007.

Firms in certain advanced biotechnology components were found to have unique advantages for developing inventions by benefit of access to specialized scientific and technological knowledge bases. The demand for "quality" may drive the selection of production technology and capital equipment investments. The findings particular to large firms, show that costs can be spread over more parts of an enterprise, enabling the undertaking of more innovative projects than found with smaller firms. The emerging picture from this analysis of the determinants of patenting in biotechnology is that the innovation process involves a well-balanced combination of inputs from both R\&D and new machinery and capital equipment.

Scientometrics 2013, 94, 497-521.

\section{Process windows for flow chemistry}

The concept of novel process windows (NPW) explores process conditions that are distant from current conventional synthetic practices. Such conditions could involve high temperatures, high pressures, high concentrations (solvent-free), new chemical transformations, explosive conditions, and process simplification. The scope of useful synthetic chemistry could be significantly expanded through integration at laboratory and production scales. The transformation intensification properties of microstructured reactors help to identify these new reactors as a possible safe means to accomplish the use of these harsh conditions in a routine fashion. New equipment and processing techniques such as micro- and other flow reactors, and flow chemistry provided the conditions to attain new operating modes. NPW offer new opportunities to synthetic chemists through reaction and chemistry innovation. The changes available through the NPW concept can extend from lab bench considerations to chemical plant scale implementation. The authors expect the merging of process chemistry, engineering, and synthetic chemistry to form a full-chain-oriented process design. Improved sustainability footprint and cost structure should flow from the 
newly organized technology. Process development time is expected to be reduced with enhanced product flexibility and product quality. Process chemical routes can be developed in a stepwise approach by employing protocols enabling transition batch considerations for continuousflow setup in the laboratory to a production environment. The feasibility study tests main process parameters such as temperature or residence time. Optimum reaction conditions are ascertained through laboratory evaluation followed by a sequence of extended run studies and eventually sample production. One example of hazardous synthetic routes is the formation of substituted tetrazoles.

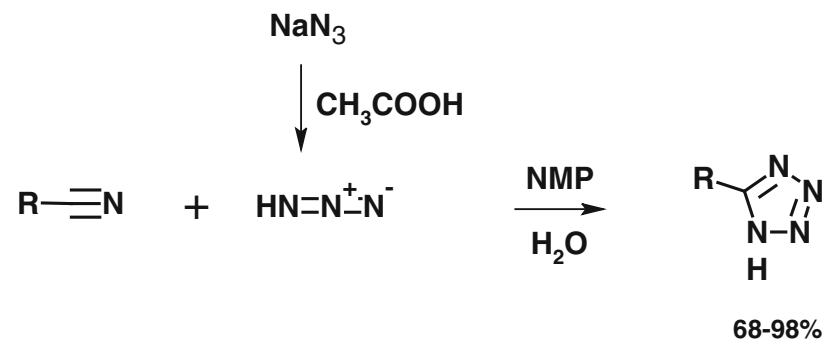

The reactant $\mathrm{HN}_{3}$ is highly explosive and extremely toxic with a low boiling point. These features require reaction conditions of very high control, i.e., low concentrations, controlled emissions, and reaction containment. A continuous-flow reaction assembly using a silica-coated stainless steel coil at $220-260{ }^{\circ} \mathrm{C}$ and 36 bar led to excellent yields for a broad range of 5 -substituted $1 H$-tetrazoles in short timeframes of 10-15 min.

Remarkable results have been found using this concept to enhance the synthesis of adipic acid a major article of commerce through process intensification. The established technology converts cyclohexane to cyclohexanol and cyclohexanone by air oxidation and then nitric acid oxidation completing the synthesis was flow sheeted. An alternate synthetic scheme utilizing cyclohexene as a starting material leads to adipic acid in a direct conversion with $30 \% \mathrm{H}_{2} \mathrm{O}_{2}$, over $\mathrm{Na}_{2} \mathrm{WO}_{2}$ and $\left[\mathrm{CH}_{3}\left(n-\mathrm{C}_{8} \mathrm{H}_{17}\right)_{3-}\right.$ $\mathrm{N} \mathrm{HSO}_{4}$ as a phase transfer catalyst offers a more compact plant design and footprint. The synthesis of adipic acid from cyclohexene, cyclohexanol, or cyclohexanone has been conducted in continuous-flow conditions in a simple flow system free of metal parts. Pure crystalline adipic acid was isolated after a simple filtration step with high degrees of selectivity. This scalable process may lead to significant benefits accrued from process efficiency, capital investment, operational costs, and process safety.<smiles>C[C@H](NO)[N+](=O)[C@H]1CCCCC1=O</smiles>

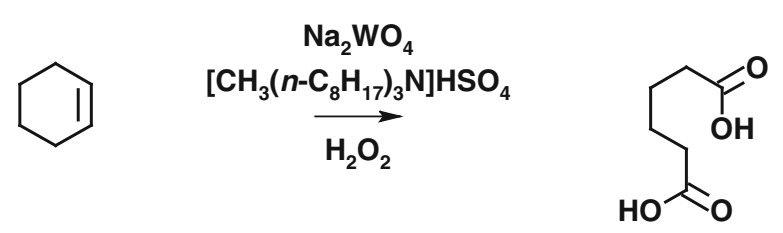

ChemSusChem 2013, 6, 746-789; 2013, 6, 978-982.

\section{Micromotors detoxify chemical threats}

A challenging task involved with the destruction of weapons of mass destruction is the development of rapid conversion technology of chemical weapons to non-toxic products. A significant problem exists with the elimination of stockpiles of chemical warfare agents (CWAs) stored at remote storage field sites where processes employing large quantities of decontaminating chemicals, extended reaction times, and controlled mechanical agitation are difficult to achieve.

Effective decontamination of the chemical agents GB (Sarin, isopropyl methylphosphonofluoridate), VX ((S)-[2(diisopropylamino)ethyl] $O$-ethyl methylphosphonothioate), GD (Soman, pinacolyl methylphosphonofluoridate), and HD (sulfur mustard) can be achieved through peroxidebased systems with specific activators (such as bicarbonate) to generate $\mathrm{OOH}^{-}$in situ for the oxidation process. The current oxidative process typically requires high peroxide concentrations (20-30\% with stoichiometric excess of 1:50), long reaction times with or without mechanical agitation. These inefficiencies clearly characterize the current technology as not suitable or undesirable for expedient field treatment of CWAs stockpiles.

It has been found that the desired CWA conversion can be accomplished through the use of self-propelled micromotors that have been demonstrated for their utility in biomedical and environmental applications. Peroxide-driven microtubular motors were developed on a templatebased electrodeposition of a poly(3,4-ethylenedioxythiophene)/Pt bilayer fabricated into 8 - $\mu \mathrm{m}$-long polymer/Pt microtubule. These constructs are efficiently propelled by the emission of oxygen bubbles for the oxidation of hydrogen peroxide at an inner Pt layer. Efficient self- 
mixing of a oxidation solution can be accomplished with the micromotors thereby accelerating the decontamination process. Lower peroxide concentrations, shorter reactions times without external stirring strengthen the attraction of the micromotor process in contrast conventional peroxide detoxification methods. A variety of independent variables were found to control the decontamination process which is important to scale up interests. This new area of research assists the objectives of process intensification and simplification with added safety features.<smiles>COP(=O)(OC)Oc1ccc([N+](=O)[O-])cc1</smiles>

Methyl paraoxon<smiles>CCOP(=O)(Cc1ccc([N+](=O)[O-])cc1)OCC</smiles><smiles>CCOP(=O)(Cc1ccc([N+](=O)[O-])cc1)OCC</smiles>

Ethyl paraoxan
Enzymes generally are expensive. One methodology to retain enzymatic activity is to immobilize the enzyme on or within a nonreactive matrix. Stability and recyclability of biocatalysts are two characteristics leading to immobilization of the enzyme rather than employing the free enzyme. Product contamination is reduced by controlling the formation of enzyme residues and lowering of allergenicity risk. Immobilization of enzymes can be accomplished by adsorption onto a support, encapsulation, and cross-linking entrapment. The activity of enzymes is<smiles>O=[N+]([O-])c1ccc(OP(=O)(O)Oc2ccc([N+](=O)[O-])cc2)cc1</smiles>

Bis(4-nitrophenyl)phosphate
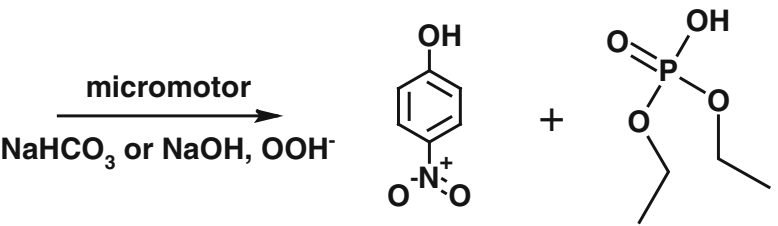

Angew Chem Int Ed 2013, 52, 50, 13276-13279.

\section{Immobilized enzymes}

Enzymes are naturally occurring catalysts found in living matter that are able to conduct specific biochemical actions supportive of the organism in which they reside. These catalysts have been employed outside their natural environment to conduct synthetic reactions that rivals chemical means to accomplish the same transformation. An established industry provides a multitude of useful enzymes for use in a wide spectrum of applications. dependent on geometrical properties that conserve enzyme activity. Temperature, $\mathrm{pH}$, and other aspects of a natural environment for enzymes are important to the stabilization of properties achieved through immobilization. A 352-page special topic issue of Chem Soc Reviews provides 16 articles addressing the practice of enzyme immobilization. There are seven tutorial reviews and nine extended reviews on various aspects of enzyme immobilization and its applications. One area of application is the use of hydrolytic enzymes to form diesel fuel from glycerol triesters. This special topic issue provides almost monographic coverage for enzyme immobilization and its uses. 
<smiles>[R]C(=O)OCC(COC([R])=O)OC([R])=O</smiles>

Glycerol triesters<smiles>OCC(O)CO</smiles>

Glycerol<smiles>[R]C(=O)OCO</smiles><smiles>[CH+]1CCCC1</smiles><smiles>[BH3-]</smiles><smiles>[R]C(=O)O[18O]</smiles><smiles>CCC(=O)O[Tl]</smiles>

Diesel fuel components

Chem Soc Rev 2013, 42, 6213-6565.

\section{Bt crop resistance development}

One of the more controversial inventions of modern biotechnology is genetically modified crops which are now found in 1 billion acres. Bacillus thuringiensis (Bt) protected crops endowed with pesticidal trait(s) through the molecular incorporation of selected DNA from the detritus inhabiting microorganism, Bt. The DNA encodes for the expression of selected proteins which are toxic to the larval form of targeted pest insects. Field monitoring data from five continents was analyzed for the detection of resistance to $B t$ crops and empirical evaluation of factors affecting the development of resistance. For populations of 5-13 major pest species, the $B t$ crops exhibited reduced efficacy when compared to the resistant populations of a single pest species in 2005 despite continued susceptibility of most pest populations. Modeling predictions are supported by the field data. Factors that delay resistance are: recessive inheritance, low initial frequency of resistance alleles, refuges of non- $B t$ crops in large numbers, and separate deployment of two-toxin $B t$ crops from the ontoxin $B t$ crops. The authors underscore the importance of proactive evaluation of inheritance and initial frequency of resistance for their utility to predict the risk of resistance and improving management strategies to sustain the useful lifetime of $B t$ crops.

Nature Biotechnol 2013, 31, 510-521.

\section{New green metrics and indices for chemical processes}

A new metric focused on the development of green chemical reactions and synthetic plans has been designated as the "benign" index (BI). Potentials for environmental harm such as acidification-basification (ABP), ozone depletion (ODP), global warming (GWP), smog formation (SFP), inhalation toxicity (INHTP), ingestion toxicity
(INGTP), inhalation carcinogenicity (INHCP), ingestion carcinogenicity (INGCP), bioconcentration (BCP), abiotic resource depletion (ABDP), cancer potency (CPP), persistence (PER), and endocrine disruption (EDP) have been incorporated into the BI. The previously use radial pentagon green metrics has been expanded to include the BI. Industrial synthetic plans for phenol, aniline, and aspirin are employed to expose the value of this new green metric analysis format. The limitations of this methodology are discussed as pertaining to proper decision making on synthetic route selection. In the case of phenol from benzene, a series of different synthetic routes are analyzed. Clearly, one of the major roadblocks to this analysis is the incompleteness of databases containing the key parameters. The author strongly argues for the use of experimentally based data for the key parameters and avoiding the use of values derived from computational methods.
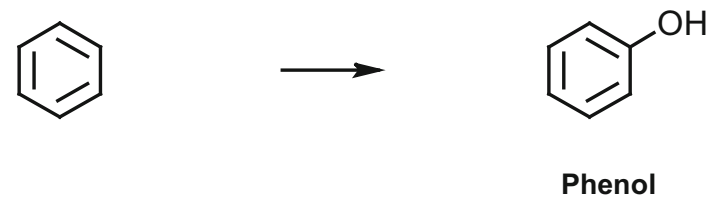

The Safety/Hazard Index (SHI) has been designed with an eye to the need for assessment of workplace safety and environmental hazards. Using themes and symbolism of the Workplace Hazardous Materials Information System (WHMIS) and National Fire Protection Association (NFPA) 704 code, the SHI integrates the following safetyhazard potentials: corrosive gas (CGP), corrosive liquid/ solid (CLP), flammability (FP), oxygen balance (OBP), hydrogen gas generation (HGP), explosion vapor (XVP), explosive strength (XSP), impact sensitivity (ISP), risk phase (RPP), occupational exposure limit (OELP), maximum allowable concentration (MACP) dermal absorption (DAP), and skin dose (SDP). Additionally, two indices are also incorporated reaction temperature hazard index 
(RTHI) and reaction pressure hazardous index (RPHI) into the SHI at ambient reaction conditions. Industrial synthetic routes to several chemicals were evaluated by the SHI index. The results are displayed as heptagonal radial diagrams to show the identification of the "greenest" route for chemicals such aniline from benzene.<smiles>c1ccccc1</smiles>

Benzene

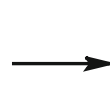

Aniline
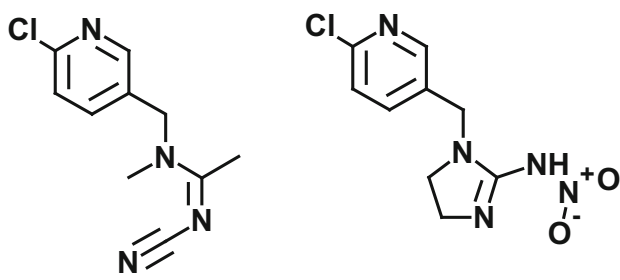

Acetamiprid<smiles>Nc1ccccc1</smiles>

environmental lifetime in the environment and thereby enhance insect controls.
$\mathrm{Cl}$<smiles>N#CN=C1SCCN1Cc1ccc(I)nc1</smiles>

Thiachloprid

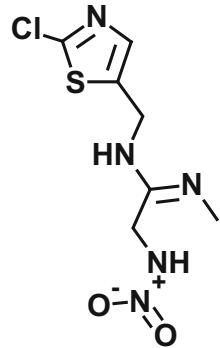

Clothiandin
Org Process Res Dev 2012, 16, 1482-1506; 2013, 17, 175-192.

\section{Bird sensitivities to insecticides}

The 97-page American Bird Conservancy's Report, The Impact of the Nation's Most Widely Used Insecticides on Birds, is available at the conservancy's website. The report investigates the effects of neonicotinoid insecticides on avian species and concludes that these chemicals are lethal to birds and the life of the aquatic ecosystems in which they live and depend. The neonicotinoids were first introduced in the 1990s due to broad pest resistance to the established insecticides and their human health effects. Directly related to the established toxicity of nicotine, neonicotinoids act on the central nervous system of insects as agonists of the neurotransmitter, acetylcholine. These insecticides as replacements of nicotine were developed to have a longer
http://www.abcbirds.org/abcprograms/policy/toxins/Neo nic_FINAL.pdf.

\section{New journal}

Current Green Chemistry has been launched as an international peer-reviewed journal providing another publication supporting the important discipline of green chemistry. This burgeoning research area has been aided by an increasing number of devoted publications. Most aspects of green chemistry are inherent in the scope of focus in the new publication. The new journal will publish review and regular research papers with a desire to have papers organized into thematic issues organized by a leading researcher. The introductory issue is available for inspection at the cited web site.

http://www.benthamsciencepublisher.com/journal/index. php?journalID=cgc. 